\title{
Cultivo agroecológico de berinjeleira sob doses de adubação orgânica em coberturas vivas perenes
}

\author{
Carlos Antonio B dos Santos'; Marcus Vinícius C Rocha²; José Antonio A Espindola ${ }^{3}$; José Guilherme M \\ Guerra $^{3}$; Dejair L de Almeida ${ }^{4}$; Raul de LD Ribeiro ${ }^{5}$ \\ ${ }^{1}$ UFRRJ, Ladeira da Meteorologia 03, 23890-000 Seropédica-RJ; agbarreto@ufrrj.br; 2Eng. Agrônomo, R. Edgar Nogueira 266, 27286- \\ 330 Volta Redonda-RJ; marcusvinicius_rocha@yahoo.com.br; ${ }^{3}$ Embrapa Agrobiologia, C. Postal 74505, 23890-000 Seropédica-RJ; jose. \\ espindola@embrapa.br (autor correspondente); guilherme.guerra@embrapa.br; ${ }^{4}$ Sítio Barra do Santa Teresa, Estrada RJ 116 km 100,

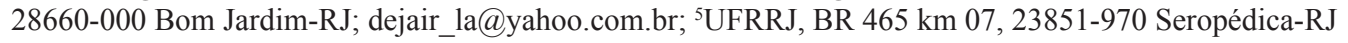

\begin{abstract}
RESUMO
O desempenho agronômico da berinjeleira foi avaliado em cultivo agroecológico, comparando-se espécies de gramínea e leguminosa perenes para cobertura viva do solo. O experimento foi conduzido no município de Seropédica-RJ, no delineamento de blocos casualizados, com parcelas subdivididas e três repetições. Foram avaliadas as coberturas vivas do solo com amendoim forrageiro (Arachis pintoi), grama batatais (Paspalum notatum) e preparo convencional do solo (controle). Nas subparcelas, foram empregadas doses crescentes de "cama" de aviário, correspondendo a 120, 240, 480 e 720 g planta $^{-1}$, aplicadas parceladamente durante o ciclo da hortaliça. A viabilidade do uso do amendoim forrageiro como cobertura viva no cultivo da berinjeleira foi demonstrada pelo fato de que os valores obtidos nesse tratamento não diferiram daqueles do preparo convencional do solo para as variáveis avaliadas (produtividade, número e peso médio de frutos). A exceção relaciona-se ao uso do amendoim forrageiro associado à maior dose de adubação orgânica (720 g de "cama" de aviário/planta), que se mostrou superior quando comparado ao preparo convencional do solo. Os valores máximos foram obtidos com as doses de "cama" de aviário estimadas em $600 \mathrm{~g} \mathrm{planta}^{-1}(60,63$ $\left.\mathrm{t} \mathrm{ha}^{-1}\right)$ e em $480 \mathrm{~g}$ planta $^{-1}\left(55,80 \mathrm{t} \mathrm{ha}^{-1}\right)$ para amendoim forrageiro e preparo convencional, respectivamente. Em contrapartida, com a grama batatais, mesmo a dose mais elevada de adubação orgânica não possibilitou alcançar máximo rendimento da cultura da berinjeleira, indicando assim competição imposta pela gramínea. Os resultados obtidos indicam viabilidade agronômica do cultivo agroecológico da berinjeleira, na cobertura viva permanente do solo com o amendoim forrageiro. O maior rendimento de berinjela associado à aplicação de "cama" de aviário foi obtido na dose de 600 g planta $^{-1}$
\end{abstract}

Palavras-chave: Solanum melongena, Arachis pintoi, Paspalum notatum, "cama" de aviário, plantas de cobertura do solo.

\begin{abstract}
Agroecological cultivation of eggplant under different doses of organic fertilization using perennial species as cover crops

Agronomic performance of eggplant was evaluated under organic management, comparing perennial grass and legume species as cover crops. The trial was carried out in Seropédica, Rio de Janeiro state, Brazil, using a randomized block design with a split plot arrangement and three replications. The evaluated treatments in the plots were forage peanut (Arachis pintoi) as cover crop, Bahia grass (Paspalum notatum) as cover crop, and conventional soil tillage (control). Split plot treatments were represented by increasing dosages of poultry litter, corresponding to $120,240,480$, and $720 \mathrm{~g} \mathrm{plant}^{-1}$, which were partitioned through the eggplant cycle. The viability of forage peanut used as living mulch for eggplants was evidenced by the fact that its results did not differ statistically from conventional soil tillage for yield, number of fruits per hectare and average fruit weight of eggplant. The only exception is related to the use of forage peanut associated to the greatest dosis of organic fertilizer $\left(720 \mathrm{~g} \mathrm{plant}^{-1}\right)$, which has shown superior results when compared to conventional soil tillage. Maximum values were obtained with poultry litter dosage of $600 \mathrm{~g} \mathrm{plant}^{-1}\left(60.63 \mathrm{tha}^{-1}\right)$ and $480 \mathrm{~g} \mathrm{plant}^{-1}\left(55.80 \mathrm{tha}^{-1}\right)$ for forage peanut and soil tillage treatments, respectively. On the other hand, Bahia grass did not allow to reach maximum eggplant yield, even at the highest dosage of poultry litter, indicating competition imposed by the cover crop. The results indicate agronomic feasibility of eggplant grown under agroecological management, with forage peanut as soil cover crop. The highest yield of eggplant was obtained with the use of 600 g plant $^{-1}$ of poultry litter.
\end{abstract}

Keywords: Solanum melongena, Arachis pintoi, Paspalum notatum, poultry litter, soil cover crops.

(Recebido para publicação em 7 de junho de 2012; aceito em 8 de abril de 2013) (Received on June 7, 2012; accepted on April 8, 2013)

\begin{abstract}
A berinjeleira (Solanum melongena) é uma hortaliça de reconhecida importância na região Sudeste. Em 2010, foram produzidos no estado do Rio de Janeiro cerca de 17.400 toneladas (EMATER-RJ, 2010). Além da alta qualidade nutricional, seus frutos possuem propriedades medicinais com-
\end{abstract}

provadas (Matsubara et al., 2005). Em conseqüência, a demanda pelo produto orgânico ou agroecológico tem se expandido nesta ultima década, abrindo inclusive, possibilidades de agregação de valor ao produto.

Dentre os sistemas agroecológicos, merecem destaque aqueles associados à agricultura orgânica. Estudos desenvolvidos revelam uma taxa de crescimento da agricultura orgânica na América Latina superior a $8,0 \%$ ao ano (Willer, 2010). Dados do Censo Agropecuário (IBGE, 2006) revelam que o Brasil apresenta cerca de 90.497 produtores orgânicos, número esse que tende a 
crescer em virtude da regulamentação da legislação sobre agricultura orgânica no país.

No estado do Rio de Janeiro, a produção orgânica ou agroecológica de hortaliças é praticada, em grande parte, por pequenos produtores de base familiar, sobretudo na região Serrana Fluminense (Guerra et al., 2007). Tais autores indicam que, em diversas áreas agrícolas dessa região, é evidente a degradação do solo por processos erosivos, em função da freqüente exploração no sistema convencional intensivo e sem sustentabilidade. Neste contexto, o manejo conservacionista do solo representa uma estratégia fundamental à sustentabilidade da produção agroecológica de hortaliças. Minimizar o revolvimento do solo contribui para a preservação de sua estrutura, principalmente no que concerne à estabilidade dos agregados e ao volume de poros, evitando perdas de solo e nutrientes provocadas pelos processos erosivos. O sistema plantio direto na palhada de pré-cultivos anuais vem sendo ultimamente pesquisado no Brasil, envolvendo várias espécies olerícolas. Pereira (2007), pesquisando o cultivo de couve-flor sobre a palhada de Crotalaria juncea em sistema plantio direto, verificaram rendimento de 56,0 $\mathrm{t} \mathrm{ha}^{-1}$. Oliveira et al. (2008) verificaram efeitos positivos no rendimento do taro em sistema plantio direto na palhada de aveia preta (Avena strigosa), associado a dose de $130 \mathrm{~kg}$ de $\mathrm{N}$ através de "cama" de aviário. Avaliando o cultivo da Crotalária juncea solteira ou consorciada com girassol (Helianthus annuus) e sorgo (Sorghum bicolor), Santos (2009) obteve produtividade do repolho variando de 62 a 74 t ha $^{-1}$. Especificamente com referência à berinjeleira, foram verificados benefícios do plantio direto na palhada de Crotalaria juncea, em sistema orgânico de produção (Castro et al., 2005).

Apesar das reconhecidas vantagens da utilização das plantas de cobertura de ciclo anual (Devide et al., 2009; Luciano et al., 2009), uma outra forma de promover adequada conservação do solo dá-se pelo emprego de certas gramíneas e leguminosas perenes para cobertura viva do solo. Essa prática cultural também confere proteção contra a erosão e contribui para a formação de agregados (Perin et al., 2002), além de incorporar expressiva quantidade de matéria orgânica e de nitrogênio ao solo (Perin et al., 2003).

Dentre as espécies vegetais empregadas para cobertura viva do solo, as leguminosas são particularmente estudadas em virtude de sua alta capacidade de aporte de nutrientes, em especial o nitrogênio via fixação biológica (Paulino et al., 2009). Algumas espécies da família das gramíneas igualmente se adequam a tal finalidade, fornecendo apreciável volume de biomassa e melhorando a estrutura do solo através de um profuso sistema radicular (Santos et al., 2007).

Com respeito às coberturas vivas do solo, estudos têm priorizado sua aplicação em pomares de frutíferas (Bremer Neto et al., 2008; Perin et al., 2009). Quanto às hortaliças, Oliveira et al. (2006a, 2006b) demonstraram viabilidade agronômica para cultivos de alface e feijão-de-vagem arbustivo em solo coberto por grama batatais (Paspalum notatum) ou amendoim forrageiro (Arachis pintoi). Foi constatado que o uso de centrosema (Centrosema pubescens), siratro (Macroptilium atropurpureum) e desmódio (Desmodium intortum), como cobertura viva do solo, não prejudicou o desempenho de espécies de hortaliças, inclusive disponibilizando nitrogênio durante o ciclo das culturas comerciais (Kleinhenz et al., 1997).

Os adubos orgânicos são amplamente recomendados na produção de hortaliças. Dentre os diversos tipos existentes, os estercos destacam-se devido aos seus efeitos positivos sobre o condicionamento do solo e na variada disponibilidade de nutrientes, especialmente N (Almeida, 1991). Com relação à adubação orgânica da berinjela, as quantidades recomendadas podem variar entre 5 e $8 \mathrm{t} \mathrm{ha}^{-1}$ de "cama" de aviário, até 20 a $30 \mathrm{t} \mathrm{ha}^{-1}$ de esterco de curral ou composto orgânico (Almeida et al., 1988). Em estudo realizado com o objetivo de avaliar o efeito de doses crescentes de esterco bovino na produtividade de berinjeleira, Cardoso et al. (2009) encontraram o maior rendimento de frutos de berinjeleira por hectare associado à dose de $48 \mathrm{t} \mathrm{ha}^{-1}$. Apesar destes resultados, não se tem verificado informações com relação à adubação orgânica de berinjeleira cultivada sobre coberturas vegetais.

O objetivo do presente estudo é avaliar o desempenho agronômico da berinjeleira, em solo com cobertura viva de grama batatais e amendoim forrageiro, variando-se doses de adubação orgânica suplementar com "cama" de aviário.

\section{MATERIAL E MÉTODOS}

O experimento foi conduzido no Sistema Integrado de Produção Agroecológica (SIPA), na "Fazendinha Agroecológica km 47", localizado no município de Seropédica ( $22^{\circ} 46^{\prime} \mathrm{S}, 43^{\circ} 41^{\prime} \mathrm{O}$, $33 \mathrm{~m}$ de altitude), Região metropolitana do estado do Rio de Janeiro. O solo da área experimental é classificado como Planossolo Háplico distrófico (Embrapa, 2006), cuja análise química $(0-20 \mathrm{~cm})$, seguindo a metodologia preconizada por Embrapa (1997), forneceu os seguintes resultados: $\mathrm{pH}(\mathrm{em}$ água $)=5,9 ; \mathrm{Al}^{+++}=$ $0,0 \mathrm{cmol}_{\mathrm{c}} \mathrm{dm}^{-3} ; \mathrm{Ca}^{++}=1,9 \mathrm{cmol}_{\mathrm{c}} \mathrm{dm}^{-3}$; $\mathrm{Mg}^{++}=1,0 \mathrm{cmol}_{\mathrm{c}} \mathrm{dm}^{-3} ; \mathrm{K}^{+}=55 \mathrm{mg} \mathrm{dm}^{-3}$; $\mathrm{P}$ disponível $=35 \mathrm{mg} \mathrm{dm}^{-3}$.

$\mathrm{O}$ delineamento adotado foi de blocos ao acaso, em parcelas subdivididas, com três repetições. Os tratamentos dispostos nas parcelas consistiram do solo coberto com espécies de ciclo perene [amendoim forrageiro (Arachis pintoi) e grama batatais (Paspalum notatum)] e do solo convencionalmente preparado com enxada rotativa acoplada a microtrator. Nas subparcelas, foram comparadas diferentes doses de “cama" de aviário (120, 240, 480 e 720 g planta ${ }^{-1}$ ). Cada uma dessas doses foi parcelada em cinco vezes, iniciando-se 30 dias após o transplante da berinjeleira e sucedendo-se a intervalos mensais. A unidade experimental foi representada por quatro plantas na área central da parcela, totalizando $3,5 \mathrm{~m}^{2}$.

As espécies para cobertura viva do solo foram introduzidas na área experimental em janeiro de 2002, utilizando-se mudas de grama batatais e sementes de amendoim forrageiro, cv. Amarillo. As mudas da gramínea foram plantadas a cada $0,1 \mathrm{~m}$ e a leguminosa na densidade de 12 sementes por metro linear, em sulcos espaçados de $0,5 \mathrm{~m}$.

Empregou-se o híbrido Ciça cujas 
mudas foram produzidas em estufa, em bandejas de isopor com 128 células. O substrato foi localmente formulado a partir de subsolo argiloso, esterco bovino e vermicomposto, misturados na proporção volumétrica de 3:2:1, respectivamente. As mudas foram transplantadas com 21 dias de idade, no espaçamento de $1,35 \times 0,65 \mathrm{~m}$. As covas com dimensões de $15 \times 15 \times 15 \mathrm{~cm}$ foram previamente adubadas com esterco bovino curtido (7,0 t ha-1 base seca), farinha de ossos (90 kg de $\left.\mathrm{P}_{2} \mathrm{O}_{5} \mathrm{ha}^{-1}\right) \mathrm{e}$ sulfato de potássio ( $110 \mathrm{~kg}$ de $\mathrm{K}_{2} \mathrm{O} \mathrm{ha}^{-1}$ ).

Durante o ciclo da berinjeleira, de abril a agosto de 2004, a temperatura média foi de $24^{\circ} \mathrm{C}$. Capinas manuais foram realizadas mensalmente nas linhas de plantio, roçando-se a grama ou o amendoim forrageiro nas entrelinhas da hortaliça, deixando-se $25 \mathrm{~cm}$ capinados junto ao coleto das plantas. No tratamento controle, as capinas envolveram a área total da parcela. Contra os insetos-pragas ("vaquinhas" e pulgões), foram efetuadas pulverizações com calda sufocálcica $(1,0 \%)$ e óleo de sementes de nim (0,5\%). Sempre que necessário, foram procedidas irrigações por meio do sistema convencional de aspersão.

Colheitas semanais da berinjela foram realizadas, selecionando-se os frutos de padrão comercial (acima de $120 \mathrm{~g}$ ). Nessas ocasiões, foram tomados dados de produtividade [obtida pela multiplicação da massa média fresca dos frutos por planta pela população de plantas na área útil (11.396 plantas/ ha)] em peso ( $\mathrm{t} \mathrm{ha} \mathrm{h}^{-1}$ ), número de frutos por hectare (obtido pela multiplicação do número de frutos totais por planta pela população de plantas na área útil (11.396 plantas/ha) e peso médio de frutos (obtido pela divisão do peso total de frutos comerciais pelo número de frutos comerciais em cada parcela).

Os valores relativos à produtividade foram submetidos à análise de variância (teste F), sendo aplicado o teste de Tukey na comparação entre médias dos tratamentos (manejo do solo) que revelaram diferenças estatisticamente significativas $(\mathrm{p} \leq 0,05)$. Quanto às fontes de variação referentes a doses de adubação com "cama” de aviário, realizou-se análise de regressão, tendo como principal critério para escolha do modelo a significância dos coeficientes da equação. A realização das análises foi feita mediante o uso do software SAEG, desenvolvido pela Universidade Federal de Viçosa.

\section{RESULTADOS E DISCUSSÃO}

Houve interação significativa entre os fatores sistema de plantio e doses de adubação para as variáveis produtividade, número de frutos por hectare e peso médio de frutos.

Para a dose de $120 \mathrm{~g}$ de "cama" de aviário, as maiores produtividades de frutos de berinjeleira foram observadas nos tratamentos de sistema convencional de preparo do solo e cobertura viva com amendoim forrageiro, superando de modo significativo aquela decorrente da cobertura com grama batatais (Tabela 1). Nos demais níveis de adubação, os resultados de produtividade foram semelhantes aos obtidos com a dose de $120 \mathrm{~g}$, com exceção da maior dose (720 g). Nesse caso, a cobertura viva de amendoim forrageiro superou em $25 \mathrm{e}$ $40 \%$ as produtividades dos tratamentos de preparo convencional do solo e a cobertura viva de grama batatais, respectivamente. Com relação às variáveis número de frutos por hectare e peso médio dos frutos, o desdobramento dos sistemas de plantio em cada nível de adubação seguiu a mesma tendência do discutido anteriormente para a variável produtividade (Tabela 1).

Cabe destacar a viabilidade do uso do amendoim forrageiro como cobertura viva no cultivo da berinjeleira. Isso se expressa principalmente pelo fato de que os valores obtidos nesse tratamento não diferiram daqueles do preparo convencional do solo para as variáveis avaliadas (produtividade, número e peso médio de frutos). A exceção relaciona-se ao uso do amendoim forrageiro associa-

Tabela 1. Média de produtividade, número de frutos por hectare e peso médio de frutos da berinjela 'Ciça', sob diferentes sistemas de plantio em diferentes doses de "cama" de aviário (average yield, number of fruits per hectare and average fruit weight of eggplant 'Ciça' in different planting systems and poultry bed manure doses). Seropédica, Embrapa Agrobiologia, 2004.

\begin{tabular}{|c|c|c|c|}
\hline \multirow{2}{*}{$\begin{array}{l}\text { Doses de "cama" } \\
\text { de aviário } \\
\text { (g/planta) }\end{array}$} & \multicolumn{3}{|c|}{ Sistema de plantio } \\
\hline & $\begin{array}{l}\text { Amendoim } \\
\text { forrageiro }\end{array}$ & $\begin{array}{c}\text { Grama } \\
\text { batatais }\end{array}$ & $\begin{array}{c}\text { Preparo } \\
\text { convencional }\end{array}$ \\
\hline & \multicolumn{3}{|c|}{ Produtividade de frutos $\left(\mathrm{t} \mathrm{ha}^{-1}\right)$} \\
\hline 120 & $24,00 \mathrm{a}^{1}$ & $1,67 \mathrm{~b}$ & $29,45 \mathrm{a}$ \\
\hline 240 & $45,67 \mathrm{a}$ & $10,34 \mathrm{~b}$ & $37,00 \mathrm{a}$ \\
\hline 480 & $57,33 \mathrm{a}$ & $19,00 \mathrm{~b}$ & $55,80 \mathrm{a}$ \\
\hline 720 & $56,00 \mathrm{a}$ & $34,18 \mathrm{~b}$ & $42,00 \mathrm{~b}$ \\
\hline \multirow[t]{2}{*}{ Média } & $45,75 \mathrm{a}$ & $16,30 \mathrm{~b}$ & $41,13 \mathrm{a}$ \\
\hline & \multicolumn{3}{|c|}{ Frutos/ha $\left(n^{0}\right)$} \\
\hline 120 & $128205 \mathrm{a}$ & $12345 \mathrm{~b}$ & $166191 \mathrm{a}$ \\
\hline 240 & $195635 \mathrm{a}$ & $66476 \mathrm{~b}$ & $177587 \mathrm{a}$ \\
\hline 480 & $199430 \mathrm{a}$ & $113960 \mathrm{~b}$ & $216524 \mathrm{a}$ \\
\hline 720 & $214624 \mathrm{a}$ & $159544 \mathrm{~b}$ & $175688 \mathrm{~b}$ \\
\hline \multirow[t]{2}{*}{ Média } & $184473 \mathrm{a}$ & $88081 \mathrm{~b}$ & $183997 \mathrm{a}$ \\
\hline & \multicolumn{3}{|c|}{ Peso médio de frutos (g) } \\
\hline 120 & $184,74 \mathrm{a}$ & $123,67 \mathrm{~b}$ & $178,22 \mathrm{a}$ \\
\hline 240 & $226,83 \mathrm{a}$ & $145,35 \mathrm{~b}$ & $219,31 \mathrm{a}$ \\
\hline 480 & $285,66 \mathrm{a}$ & $165,63 b$ & $259,56 \mathrm{a}$ \\
\hline 720 & $263,83 \mathrm{a}$ & $205,57 \mathrm{~b}$ & $228,34 \mathrm{~b}$ \\
\hline Media & $240,26 \mathrm{a}$ & $160,05 \mathrm{~b}$ & $221,35 \mathrm{a}$ \\
\hline
\end{tabular}

${ }^{1}$ Os valores representam médias de três repetições; médias seguidas de mesmas letras, nas linhas, não diferem entre si pelo teste de Tukey $(\mathrm{p} \leq 0,05)\left[{ }^{1}\right.$ values represent average of three replications; same latters in lines indicate mean values not differing by Tukey test $(p \leq 0,05)]$. 


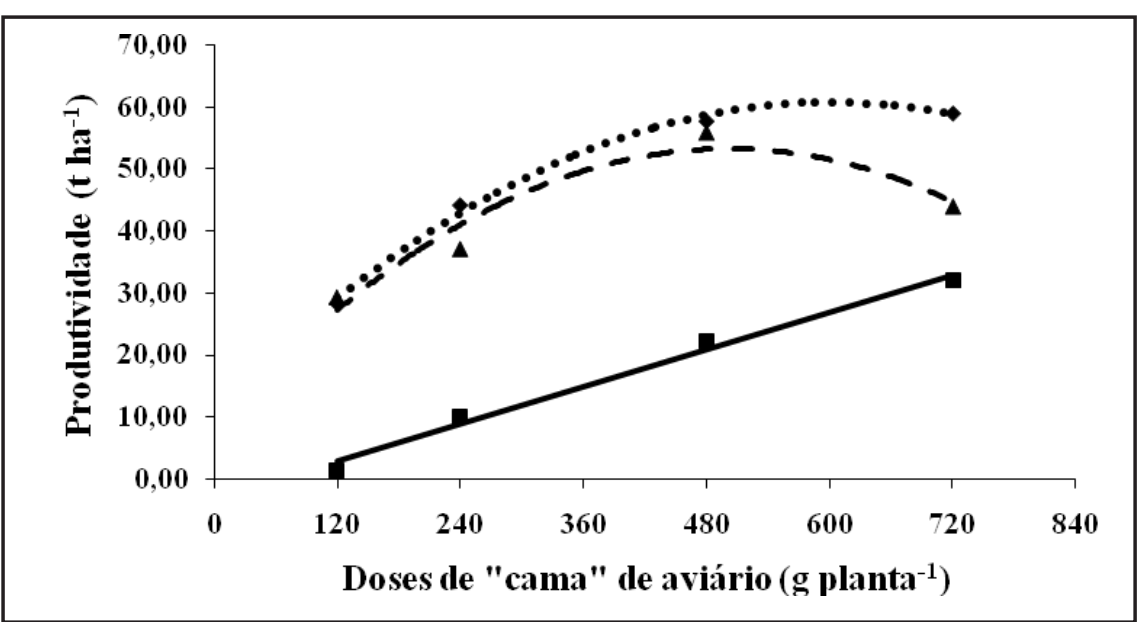

Figura 1. Efeito de doses de "cama" de aviário, aplicada parceladamente, na produtividade da berinjela 'Ciça' ( $\left(\mathrm{tha}^{-1}\right)$, sob manejo orgânico em diferentes sistemas de plantio (effect of poultry litter manure doses, partilly applied, on agronomic performance of eggplant, cv. Ciça $\left(\mathrm{t} \mathrm{ha}^{-1}\right)$, organically grown in different planting systems. Seropédica, Embrapa Agrobiologia, 2004.

${ }^{1}$ Cobertura viva do solo com amendoim forrageiro, Arachis pintoi (live mulching with forage peanut, Arachis pintoi) ( $\$)$; cobertura viva do solo com grama batatais, Paspalum notatum (live mulching with Bahia grass, Paspalum notatum (๘); preparo convencional do solo com enxada rotativa (traditional soil tillage with rotary hoe) $(\boldsymbol{\Delta})$.

do à maior dose de adubação orgânica, que se mostrou superior quando comparado ao preparo convencional do solo.

Por sua vez, a cobertura viva de grama batatais somente não demonstrou potencial mais reduzido de produção do híbrido Ciça no maior nível de adubação, onde se mostrou estatisticamente equivalente ao sistema de preparo convencional do solo. Isso evidencia a possibilidade de uso desta gramínea como cobertura viva do solo no cultivo da hortaliça, desde que sejam utilizadas doses maiores de adubação orgânica em cobertura. Deve-se ressaltar que estas espécies de gramínea, às vezes, formam campos naturais, aumentado ainda mais a sua viabilidade.

Os efeitos benéficos associados ao uso da cobertura viva com amendoim forrageiro ou com grama batatais, desde que seja feita a adubação orgânica em doses adequadas, têm sido relatados quanto a diferentes aspectos como conservação do solo e da água ( $\mathrm{Li}$ et al., 2011); produção de biomassa e acumulo de nutrientes (Perin et al., 2003); controle alternativo de plantas espontâneas (Santos et al., 2008). Além desses benefícios, a cobertura viva com amendoim forrageiro permite o aporte de expressivas quantidades de nitrogênio produtividade da berinjeleira para todas as variáveis analisadas.

A produtividade de frutos de valor comercial em função das doses de "cama" de aviário seguiu um modelo quadrático para o amendoim forrageiro $\left[\mathrm{Y}=11,284+0,164 \mathrm{X}-0,000136 \mathrm{X}^{2}\right.$ $\left.\left(\mathrm{r}^{2}=0,97\right)\right]$ e o preparo convencional do solo $[Y=8,990+0,187 \mathrm{X}-0,000187$ $\left.\mathrm{X}^{2}\left(\mathrm{r}^{2}=0,92\right)\right]$. Dessa forma, os valores máximos corresponderam à dose de 600 e a 480 g planta $^{-1}$, respectivamente, para o plantio na cobertura de amendoim forrageiro $\left(60,63 \mathrm{t} \mathrm{ha}^{-1}\right)$ e para o preparo convencional $\left(55,80 \mathrm{t} \mathrm{ha}^{-1}\right)$ (Figura 1). Em contrapartida, na cobertura de grama batatais obteve-se correlação linear com as doses de "cama" de aviário $[\mathrm{Y}=-3,994+0,0517 \mathrm{X}(\mathrm{r} 2=0,98)]$. Assim, mesmo com a dose mais elevada de "cama" de aviário, o máximo rendimento de frutos comerciais não foi alcançado, o que reforça a hipótese de efeito competitivo entre as espécies. Segundo Vargas \& Roman (2006), espécies com rota fotossintética $\mathrm{C} 4$ tendem a apresentar vantagem competitiva em relação à eficiência de uso de recursos naturais quando comparadas a espécies C3. Assim, a grama batatais (C4) pode ocasionar maior competição com a berinjeleira (C3), reduzindo sua produtividade, o que não se verificou para o amendoim forrageiro por se tratar de uma espécie C3. No entanto, Univer et al. (2009) destacam que o emprego de coberturas vivas com gramíneas pode favorecer aumentos de produtividade de olerícolas como o morango. Assim, outros estudos tornam-se necessários para determinar estratégias de manejo que viabilizem a cobertura viva com grama batatais para a berinjela. Variações na forma de aplicação do adubo orgânico, número de parcelamentos, dose do adubo orgânico e distância de limpeza do coleto até a grama podem influenciar a produtividade obtida.

Os resultados obtidos com número de frutos de padrão comercial produzidos por hectare, podem ser descritos pelas equações: $Y=93048,710+423,970 \mathrm{X}$ - $0,364 \mathrm{X}^{2}\left(\mathrm{r}^{2}=0,89\right)$, para amendoim forrageiro; $Y=-2993,870+233,527 X$ $\left(\mathrm{r}^{2}=0,97\right)$, para grama batatais; e $\mathrm{Y}=118436,320+415,930 \mathrm{X}-0,44059 \mathrm{X}^{2}$ $\left(\mathrm{r}^{2}=0,96\right)$, para preparo convencional 


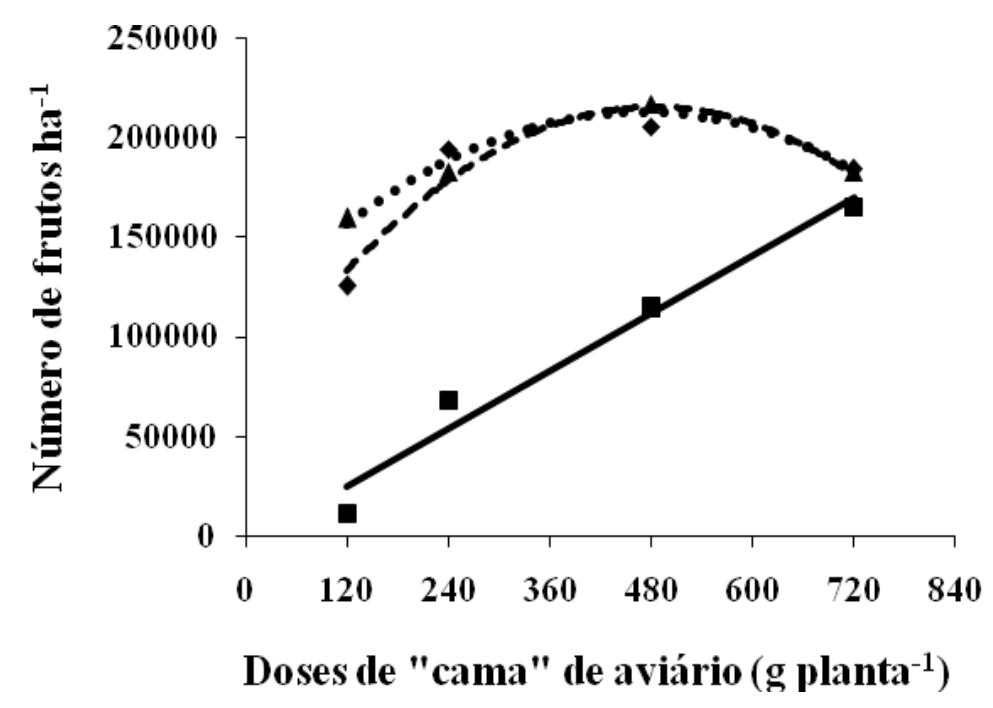

Figura 2. Efeito de doses de "cama" de aviário aplicada parceladamente, na produtividade da berinjela 'Ciça' (número de frutos/ha), sob manejo orgânico em diferentes sistemas de plantio (effect of poultry litter manure doses, partially applied, on agronomic performance of eggplant, cv. Ciça (number of fruits ha-1), organically grown in different planting systems. Seropédica, Embrapa Agrobiologia, 2004.

${ }^{1}$ Cobertura viva do solo com amendoim forrageiro, Arachis pintoi (live mulching with forage peanut, Arachis pintoi) ( $\$)$; cobertura viva do solo com grama batatais, Paspalum notatum (live mulching with Bahia grass, Paspalum notatum (匹); preparo convencional do solo com enxada rotativa (traditional soil tillage with rotary hoe) $(\boldsymbol{\Delta})$.

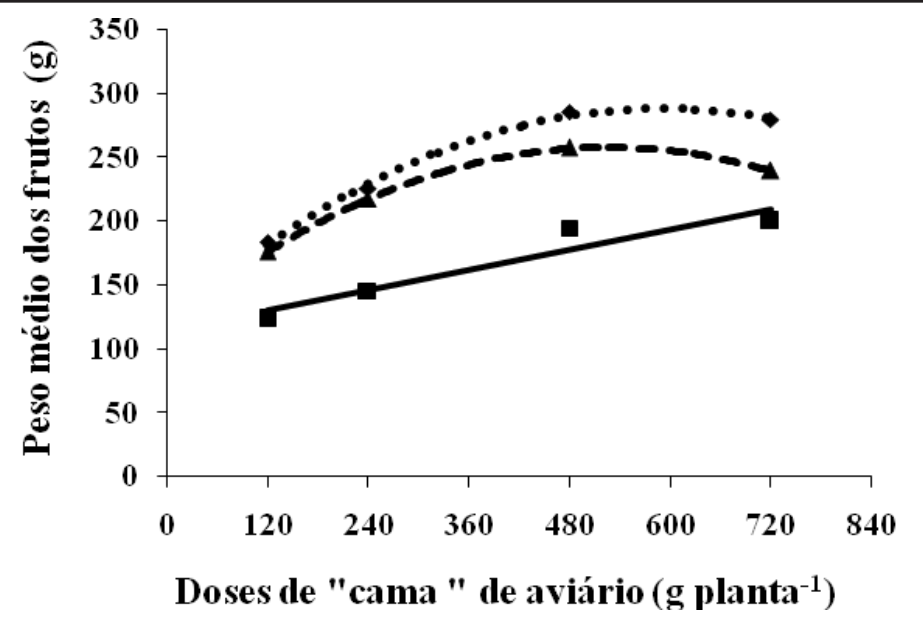

Figura 3. Efeito de doses de "cama" de aviário, aplicada parceladamente, no peso médio de frutos comerciais da berinjela 'Ciça', sob manejo orgânico em diferentes sistemas de plantio (effect of poultry litter manure doses, partially applied, on mean weight of commercial fruits of eggplant, cv. Ciça, organically grown in different planting systems). Seropédica, Embrapa Agrobiologia, 2004.

${ }^{1}$ Cobertura viva do solo com amendoim forrageiro, Arachis pintoi (live mulching with forage peanut, Arachis pintoi) ( $\$$ ); cobertura viva do solo com grama batatais, Paspalum notatum (live mulching with Bahia Grass, Paspalum notatum) (ם); preparo convencional do solo com enxada rotativa (traditional soil tillage with Rotary hoe) $(\boldsymbol{\Delta})$.

do solo. As doses ótimas do fertilizante orgânico foram estimadas em 480 e em $590 \mathrm{~g} \mathrm{planta}^{-1}$ respectivamente, para o solo sem cobertura (216.570 frutos ha-1) e para plantio na cobertura de amendoim forrageiro (216.524 frutos ha ${ }^{-1}$ ) (Figura 2). Já na cobertura formada pela grama batatais, o valor teto (165.145 frutos $\mathrm{ha}^{-1}$ ) foi equivalente à dose mais elevada de "cama" de aviário aplicada (720 g planta $\left.{ }^{-1}\right)$, novamente sinalizando o marcante efeito competitivo associado àquele tipo de cobertura de solo.

Com relação ao peso médio de frutos de padrão comercial produzidos por planta de berinjela, foram obtidas as seguintes equações: $\mathrm{Y}=110,811+$ $0,6735 X-0,000641 X^{2}\left(r^{2}=0,99\right)$, para amendoim forrageiro; $\mathrm{Y}=105,333+$ $0,1478 \mathrm{X}\left(\mathrm{r}^{2}=0,96\right)$, para grama batatais; e $Y=120,235+0,5253 X-0,000499 X^{2}$ $\left(r^{2}=0,99\right)$, para preparo convencional do solo. Da da mesma forma que para as demais variáveis, os valores mais altos associaram-se, à cobertura de amendoim forrageiro e ao preparo convencional do solo, independentemente da dose de adubação aplicada em cobertura (Tabela 1). Com relação às doses ótimas do fertilizante orgânico, 525 e 526 g planta ${ }^{-1}$, foram os valores estimados respectivamente, para plantio direto na cobertura de amendoim forrageiro (287,76 g) e para o preparo convencional $(258,48$ g) (Figura 3). Para a cobertura formada pela grama batatais, o maior peso médio $(211,75 \mathrm{~g})$ foi equivalente à dose mais elevada de "cama" de aviário aplicada (720 g planta $\left.{ }^{-1}\right)$.

Em conclusão, os resultados obtidos indicam viabilidade agronômica do cultivo agroecológico da berinjeleira, Ciça, na cobertura viva permanente do solo com o amendoim forrageiro. Essa prática favoreceu valores de produtividade que não diferiram daqueles encontrados com o preparo convencional do solo, possibilitando benefícios adicionais como o aporte de biomassa ao solo. $\mathrm{O}$ maior rendimento de berinjela associado à aplicação de "cama" de aviário foi obtido na dose de $600 \mathrm{~g}_{\text {planta }}{ }^{-1}$.

\section{REFERÊNCIAS}

ALMEIDA DL. 1991. Contribuição da adubação orgânica para a fertilidade do solo. Seropédica: UFRRJ. 192p. (Tese doutorado).

ALMEIDA DL; SANTOS GA; DE-POLLI H; CUNHA LH; FREIRE LR; AMARAL SOBRINHO NMB; PEREIRA NNC; EIRA PA; BLOISE RM; SALEK RC. 1988. Manual de adubação para o Estado do Rio de Janeiro. Itaguaí: UFRRJ. 179p. (Coleção Universidade Rural. Série Ciências Agrárias, 2).

BREMER NETO H; VICTORIA FILHO R; MOURÃO FILHO FAA; MENEZES GM; 
CANALI E. 2008. Estado nutricional e produção de laranjeira 'Pêra' em função da vegetação intercalar e cobertura morta. Pesquisa Agropecuária Brasileira 43: 29-35.

CARDOSO MO; OLIVEIRA AP; PEREIRA WE; SOUZA AP. 2009. Eggplant growth as affected by cattle manure and magnesium thermophosphate in association with cow urine. Horticultura Brasileira 27: 307-313.

CASTRO CM; ALMEIDA DL; RIBEIRO RLD; CARVALHO JF. 2005. Plantio direto, adubação verde e suplementação com esterco de aves na produção orgânica de berinjela. Pesquisa Agropecuária Brasileira 40: $495-$ 502.

DEVIDE ACP; RIBEIRO RLD; VALLE TL; ALMEIDA DL; CASTRO CM; FELTRAN JC. 2009. Produtividade de raízes de mandioca consorciada com milho e caupi em sistema orgânico. Bragantia 68: 145-153.

EMATER-RJ (Empresa de Assistência Técnica e Extensão Rural do Estado do Rio de Janeiro). 2010. Acompanhamento Sistemático da Produção Agrícola (ASPA). Disponível em: http://www.emater.rj.gov.br/tecnica.asp. Acesso em: 20 de dez. 2011.

EMBRAPA. Centro Nacional de Pesquisa de Solos. 1997. Manual de métodos de análise de solo. 2. ed. Rio de Janeiro. 212p. (EMBRAPACNPS. Documentos, 1).

EMBRAPA. Centro Nacional de Pesquisa de Solos. 2006. Sistema brasileiro de classificação de solos. 2. ed. Rio de Janeiro. 306p.

ESPINDOLA JAA; GUERRA JGM; PERIN A; TEIXEIRAMG; ALMEIDA DL; URQUIAGA S; BUSQUET RNB. 2006. Bananeiras consorciadas com leguminosas herbáceas perenes utilizadas como coberturas vivas. Pesquisa Agropecuária Brasileira 41: 415420.

GUERRA JGM; NDIAYE, A; ASSIS, RL; ESPINDOLA, JAA. 2007. Uso de plantas de cobertura na valorização de processos ecológicos em sistemas orgânicos de produção na região serrana fluminense. Agriculturas 4: $24-28$.

INSTITUTO BRASILEIRO DE GEOGRAFIA E ESTATÍSTICA. Censo agropecuário 2006. Rio de Janeiro: IBGE, 1996. Disponível em: http:// www.ibge.gov.br/home/estatistica/economia/ agropecuaria/censoagro/brasil_2006/tab_ brasil/tab12.pdf.

KLEINHENZ V; SCHNITZLER WH; MIDMORE DJ. 1997. Effects of legume live-mulch on crop performance, soil available nitrogen and crop $\mathrm{N}$ status in intensive tropical vegetable production. Biological Agriculture and Horticulture 14: 261-278.

LI X; ZHANG Z; YANG J; ZHANG G; WANG B. 2011. Effects of Bahia grass cover and mulch on runoff and sediment yield of sloping red soil in southern China. Pedosphere 21: 238-243.

LUCIANO RV; BERTOL I; BARBOSA FT; VÁSQUEZ EV; FABIAN EL. 2009. Perdas de água e solo por erosão hídrica em duas direções de semeadura de aveia e ervilhaca. Revista Brasileira de Ciência do Solo 33: 669-676.

MATSUBARA K; KANEYUKI T; MIYAKE T; MORI, M. 2005. Antiangiogenic activity of nasunin, an antioxidant anthocyanin, in eggplant peels. Journal of Agricultural and Food Chemistry 53: 6272-6275.

OLIVEIRA FL; GUERRA JGM; ALMEIDA DL; RIBEIRO RLD; SILVA EE; SILVA VV; ESPINDOLA JAA. 2008. Desempenho de taro em função de doses de cama de aviário, sob sistema orgânico de produção. Horticultura Brasileira 26: 149-153.

OLIVEIRA NG; DE-POLLI H; ALMEIDA DL; GUERRA JGM. 2006a. Plantio direto de alface adubada com "cama" de aviário sobre coberturas vivas de grama e amendoim forrageiro. Horticultura Brasileira 24: $112-$ 117.

OLIVEIRA NG; DE-POLLI H; ALMEIDA DL; GUERRA, JGM. 2006b. Feijãovagem semeado sobre cobertura viva perene de gramínea e leguminosa e em solo mobilizado, com adubação orgânica. Pesquisa Agropecuária Brasileira 41: 1361-1367.

PAULINO GM; ALVES BJR; BARROSO DG; URQUIAGA S; ESPINDOLA JAA. 2009. Fixação biológica e transferência de nitrogênio por leguminosas em pomar orgânico de mangueira e gravioleira. Pesquisa Agropecuária Brasileira 44: 1598-1607.

PEREIRAAJ. 2007. Caracterização agronômica de espécies de Crotalaria L. em diferentes condições edafoclimáticas e contribuição da adubação verde com $\mathrm{C}$. juncea no cultivo orgânico de brássicas em sistema de plantio direto. Seropédica: UFRRJ. 72p. (Tese doutorado).

PERIN A; GUERRA JGM; TEIXEIRA MG; PEREIRA MG; FONTANA A. 2002. Efeito da cobertura viva com leguminosas herbáceas perenes na agregação de um argissolo. Revista Brasileira de Ciência do Solo 26: 713-720.

PERIN A; GUERRA JGM; TEIXEIRA MG. 2003. Cobertura do solo e acumulação de nutrientes pelo amendoim forrageiro. Pesquisa Agropecuária Brasileira 38: 791-796.

PERIN A; GUERRA JGM; ESPINDOLA JAA; TEIXEIRA MG; BUSQUET RNB. 2009. Desempenho de bananeiras consorciadas com leguminosas herbáceas perenes. Ciência \& Agrotecnologia 33: 1511-1517.

SANTOS CAB. 2009. Consórcios de espécies de cobertura de solo para adubação verde antecedendo ao cultivo de milho e repolho sob manejo orgânico. Seropédica: UFRRJ. 66p. (Dissertação mestrado).

SANTOS JCF; MARCHI G; MARCHI ECS. 2008. Cobertura do solo no controle de plantas daninhas do café. Brasília: Embrapa Cerrados. 56 p. (Embrapa Cerrados. Documentos 226).

SANTOS RSM; OLIVEIRA IP; MORAIS RF; URQUIAGA S.; BODDEY RM; ALVES BJR. 2007. Componentes da parte aérea e raízes de pastagens de Brachiaria spp. em diferentes idades após a reforma, como indicadores de produtividade em ambiente de Cerrado. Pesquisa Agropecuária Tropical 37: 119-124.

UNIVER T; PÕRK K; UNIVER N. 2009. Living grass mulches in strawberry cultivation. Agronomy Research 7: 532-535.

VARGAS L; ROMAN ES. 2006. Manejo e controle de plantas daninhas na cultura da soja. Passo Fundo: Embrapa Trigo. (Embrapa Trigo. Documentos Online, 62). Disponível em: http://www.cnpt.embrapa.br/biblio/ do/p_do62.pdf.

WILLER H. Organic agriculture worldwide: the main results of the FiBL-IFOAM survey 2010. Disponível em: http://www.ifoam.org. Acessado em 30/12/2011. 